Nigerian Journal of Physiological Sciences 24 (1): 73-78 @ Physiological Society of Nigeria, 2009 Available online/abstracted at http://www.biolineinternational.org.br/nps; www.ajol.info/journals.njps; www.cas.org

\title{
THE COMPARATIVE EFFECTS OF CHRONIC CONSUMPTION OF KOLA NUT (Cola nitida) AND CAFFEINE DIETS ON LOCOMOTOR BEHAVIOUR AND BODY WEIGHTS IN MICE
}

\author{
E. B. UMOREN, E. E. OSIM AND P. B. UDOH ${ }^{1}$
}

\begin{abstract}
Department of Physiology, College of Medical Sciences, University of Calabar, Calabar, Nigeria
${ }^{1}$ Department of Zoology and Environmental Biology, Faculty of Sciences, University of Calabar, Calabar, Nigeria. E-mail: lizzyumoren@yahoo.com
\end{abstract}

Summary: The comparative effects of chronic (28 days) consumption of kola nut and its active constituent, caffeine diets on locomotor behaviour and body weights in mice were investigated. 30 adult Swiss white mice (15$30 \mathrm{~g}$ body weight), were used for the study. The open field-maze was employed for the evaluation of locomotor behaviour. Mice in the control group $(\mathrm{n}=10)$ were fed normal rodent chow, mice in the kola nut-fed group $(\mathrm{n}=10)$ were fed kola diet $(25 \% \mathrm{wt} / \mathrm{wt}$ of rodent chow) while those in the caffeine-fed group $(\mathrm{n}=10)$ were fed caffeine diet $(0.66 \% \mathrm{wt} / \mathrm{wt}$ of rodent chow) for 4 weeks. All animals were allowed free access to clean drinking water. Daily food intake, water intake and body weight change were also measured. Daily food intake in the kola nut and caffeine-fed group of mice was significantly $(\mathrm{P}<0.001$ respectively) lower than the control. There was also a significant $(\mathrm{P}<0.001)$ decrease in daily water intake in the caffeine-fed group compared to the control whereas, the apparent decrease of water intake in the kola nut-fed group was not significantly different from the control. Body weight change was also significantly $(\mathrm{P}<0.001$ and $\mathrm{P}<0.05$ respectively) lower in the kola nut and caffeine-fed groups of mice when compared to the control. The frequency of rearing in the open field was significantly $(\mathrm{P}<0.01)$ lower in the caffeine-fed group of mice when compared to the control. The frequency of grooming was also significantly $(\mathrm{P}<0.05)$ lower in the caffeine-fed group of mice when compared to the control. There was also a significant $(\mathrm{P}<0.05)$ decrease in the frequency of light-dark transitions in the light/dark transition box for the caffeine-fed group when compared to the control. The results showed that chronic consumption of kola nut and caffeine diets caused decrease in food intake and body weight. Consumption of caffeine-diet also significantly decreased water intake and locomotor activity. The effect of kola nut-diets on water intake and locomotor activity was not significant. Hence, the effect of kola nut on locomotor behaviour and water intake may not be due to caffeine only.

Key Words: Kola nut, caffeine, food and water intake, body weight, locomotion.

\section{Introduction}

Kola nut (Cola nitida), a central nervous system stimulant has been shown to mediate some physiological effects that are similar to the action of caffeine (Carrillo and Bennitez, 2000). Kola nuts have been used in folk medicine as an aphrodisiac and an appetite suppressant, enabling African soldiers who chew them to travel long distances without food. (Trindall, 1997). Kola nut has a marked stimulating effect on the human consciousness. This effect may be used in alleviating nervous debility. It can also aid in alleviating depression and may in some people, give rise to euphoric states. Other uses include increasing the capacity for physical exertion and for enduring fatigue without food, stimulating a weak heart, despondency, brooding, anxiety and sea sickness (The Psychoactive Encyclopedia (T.P.E), 2008).

Kola nut contain caffeine among many other principles. Caffeine, theophylline, and theobromine are naturally occurring plant alkaloids referred to as methylxanthines. Methylxanthines share the ability to relax smooth muscles, stimulate the central nervous system (CNS), and produce diuresis. Caffeine exerts pharmacological effects on multiple organ systems in the body, and the other principal methylxanthines have similar effects, although potencies for specific effects vary. It is generally believed that most of the actions of kola nuts are attributable to caffeine. Inspite of many actions of kola nuts and caffeine, there are no reports on their effect on locomotor activity and body weight. Since they are nervous system stimulants, it is likely that they may affect locomotor activity and body weight. Therefore, this study determines and compares the effects of chronic consumption of kola nuts and its active principle, caffeine on locomotor behaviour and body weight using the mouse. Their comparative effects on food and water intake were also studied. 


\section{Materials and Methods}

\section{Experimental Animals}

Thirty (30) adult Swiss white mice weighing between 15-30g obtained from the disease free stock of the animal house, Department of Pharmacology, College of Medical Sciences, University of Calabar, Nigeria were used for the study. The animals were randomly assigned into three (3) groups of ten (10) animals per group. Each mouse in a study group was individually housed in a plastic cage with iron gauze bottom grid and a wire screen top. The animal room was adequately ventilated, and kept at room temperature and relative humidity of $26 \pm 2^{\circ} \mathrm{c}$ and 40 $70 \%$ respectively with 12 hour natural light-dark cycle.

\section{Treatment Regimen}

The animals were fed ad libitum with water and normal rat feed (Livestock feeds Nig. Ltd., Lagos, Nigeria). Good hygiene was maintained by constant cleaning and removal of faeces and spilled feed from cages daily. The control group (A) received normal rat feed and clean drinking water daily. The kola nutdiet group (B) received normal rat feed mixed with ground dried kola nut as described below and allowed clean drinking water freely. The caffeine-diet group (C) received normal rodent feed mixed with powdered caffeine as described below and allowed clean drinking water freely. The experiments were conducted between the hours of $1.00 \mathrm{pm}$ and $2.00 \mathrm{pm}$ daily.

\section{Preparation of kola nut-diet:}

Fresh kola nuts (Cola nitida) were obtained from the Bogobiri market, Calabar, Nigeria and used for the study. The kola nuts were washed, and dried at $60^{\circ} \mathrm{c}$ for 12 hours, and ground using electric Kenwood blender. $25 \mathrm{~g}$ of the kola nut was mixed with $75 \mathrm{~g}$ of normal rat feed in a ratio of $1: 3$ by weight respectively (Osim and Udia, 1993). A mortar/pestle was used to blend the mixture to form the kola nut-diet. The kola nut-diet was administered to group B on daily basis.

\section{Preparation of caffeine-diet:}

Synthetic caffeine, a white powder crystalline substance obtained from May and Baker (M\&B) United Kingdom, was used for the study. Kola nuts were dried to constant weight in an oven at $60^{\circ} \mathrm{C}$. From the estimation of the caffeine content of kola nuts according to the method used by Somorin (1973) and confirmed by Eka (1971), 60g of the dry nuts used for these studies contained about $1.0 \mathrm{~g}$ of caffeine. A caffeine-diet was prepared by using a spatula and a weighing balance to measure $1.0 \mathrm{~g}$ of the powdered caffeine, mixed with $150 \mathrm{~g}$ of normal rat feed. So, the amount of caffeine added was equivalent to that contained in the kola nuts given previously. A mortar/pestle was used to blend the mixture to form the caffeine-diet. This preparation was done each week (for a period of 4 weeks). The caffeine-diet was administered to group $\mathrm{C}$ on daily basis.

Experimental protocol using the open field-maze:

The open field test was used to provide measures of locomotion, exploration and anxiety (Walsh and Cummins, 1976). The experiment was performed in an enclosed laboratory to screen the animals from noise and provide dim light to avoid distraction of the animals. The animals were placed in the centre of the maze and allowed to explore the open field for 5 minutes. Before introducing each animal, the floor of the maze was cleaned using $70 \%$ ethyl alcohol in order to eliminate olfactory influences. The following behaviours were scored during the 5 minutes to assess locomotor and exploratory behaviours: line crossing, rearing and grooming.

Experimental protocol using the light/dark (LD) transition box:

The light and dark transition box is a test of locomotion and exploratory behaviour. Each mouse was picked up using a plastic bucket and placed in the centre division of the large compartment facing the floor. The mouse was allowed to explore the transition box for 5 minutes. Entering into a chamber is defined as the placement of all four paws in the chamber. During the period of 5 minutes, behaviour scored using a stopwatch was frequency of line crossing.

Statistical Analysis:

Data collected were expressed as mean \pm standard error of mean (SEM), analysis of variance (ANOVA) and the student " $\mathrm{t}$ " test were used for analysis. Values of $\mathrm{p}<0.05$ were regarded as significant.

\section{RESULTS}

Water intake

The caffeine-fed group of mice had less mean water intake when compared to the control $(\mathrm{P}<0.001)$ and kola nut-fed group of mice $(\mathrm{P}<0.01)$. Water intake appeared lower in the kola nut-fed group but was not significantly different when compared to the control group. Figure 1

\section{Food intake and body weight changes}

There was a decrease in food intake in both the kola nut-fed group and caffeine-fed group of mice 
when compared to the control ( $\mathrm{P}<0.001$ respectively). The food intake in the kola nut-fed group of mice was also lower when compared to the caffeine-fed group of mice $(\mathrm{P}<0.001)$ Figure 2 . There was a marked decrease in body weight in the kola nut-fed group of mice when compared to the control $(\mathrm{P}<0.001)$. The body weight in the caffeine-fed group of mice also decreased significantly compared to the control although not as much as the kola nut-fed group $(\mathrm{p}<0.05)$ Figure 3.

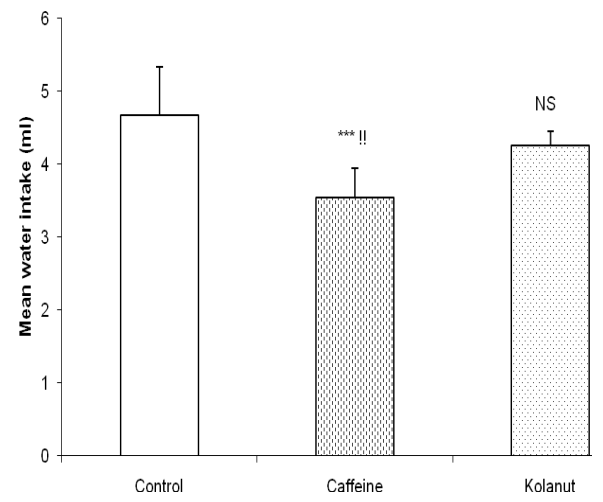

NS - Not significant compared to control $* * *$ - Significant at $p<0.001$ compared to control, !! - Significant at $p<$ 0.01 compared to kolanut. Control: $n=9$; Kola nut $: n=6$; Caffeine: $n=8$

Fig. 1: Daily water intake for kola nut, caffeine fed group of mice as compared to the control group.

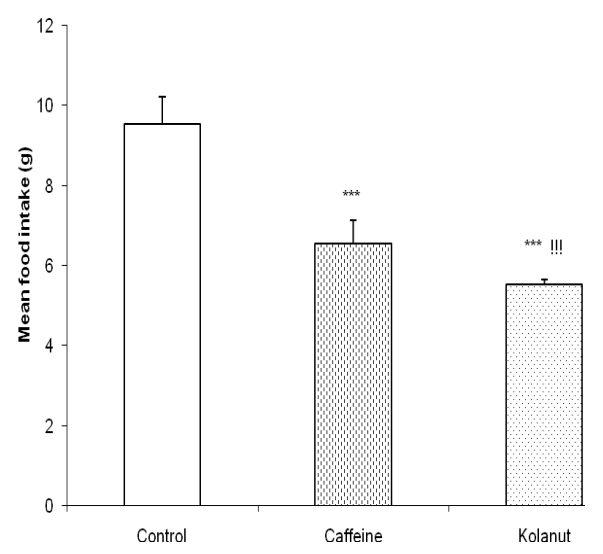

*** - Significant at $p<0.001$ compared to control, !!!! Significant at $p<0.001$ compared to caffeine. Control: $n=$ 9; Kola nut: $n=6$; Caffeine: $n=8$

Fig. 2: Daily food intake for kola nut, caffeine fed group of mice as compared to the control.

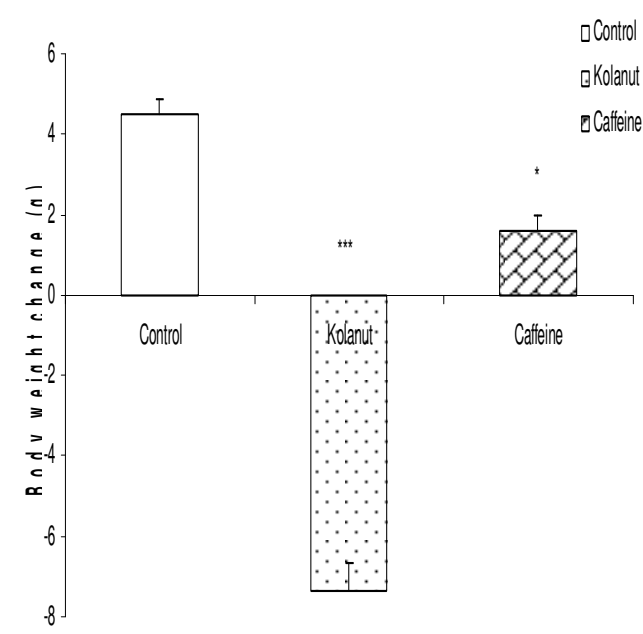

$*=$ Significant at $P<0.05$ compared to the control; *** Significant at $P<0.001$ compared to the control; Control: $n=9 ;$ Kola nut: $n=6$; Caffeine: $n=8$

Fig.3: Mean body weight change comparison among the control, kola nut and caffeine fed groups of mice.

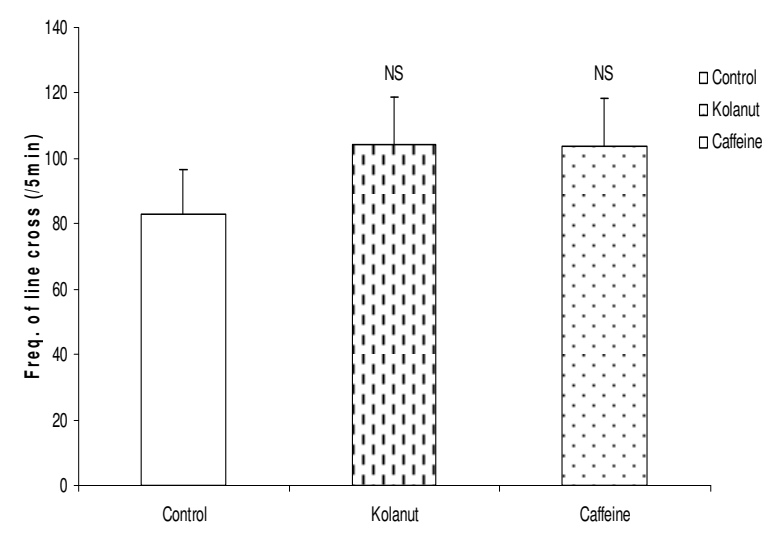

NS- Not significant compared to the control

Fig.4: Comparison of frequency of line cross in the open field apparatus for mice fed kola nut and caffeine diets and the control.

\section{Open field-maze:}

The frequency of line cross in the kola nut-fed group of mice was $104.25 \pm 14.68 / 5 \mathrm{~min}$ session. This was not significantly different from the control which was $82.90 \pm 13.65 / 5 \mathrm{~min}$ session. The frequency of line cross for the group of mice fed caffeine-diet was $103.67 \pm 14.50 / 5 \mathrm{~min}$ session. This was also not 
significantly higher when compared to the control and kola nut-fed groups of mice (Figure 4).

The frequency of rearing for the group of mice fed kola nut-diet was $44.50 \pm 4.44 / 5 \mathrm{~min}$ session. This was not significantly different when compared to the control group of mice which was $44.00 \pm 4.87 / 5 \mathrm{~min}$ session. However, the frequency of rearing for the caffeine-fed group of mice $(24.44 \pm 3.27 / 5 \mathrm{~min})$ was significantly lower compared to control $(\mathrm{p}<0.01)$. This was also significantly lower compared to the frequency of rearing for the kola nut-fed group of mice $(\mathrm{p}<0.01$; Figure 5$)$.

The frequency of grooming in the kola nut-fed mice was $2.75 \pm 0.47 / 5 \mathrm{~min}$ session. This was not significantly different from that in the control group which was $2.56 \pm 0.38 / 5 \mathrm{~min}$ session. However, the frequency of grooming for the caffeine-fed mice was $1.71 \pm 0.25 / 5 \mathrm{~min}$ session. This was significantly lower when compared to the control group $(\mathrm{p}<0.05)$. This was also significantly lower when compared to the frequency of grooming for the kola nut-fed group of mice ( $<<0.05$; Figure 6). Light/dark transition box

The mean frequency of light and dark transitions in the kola nut-fed group of mice was $9.950 \pm 2.90 / 5 \mathrm{~min}$ session. This was not significantly different from the control group which was $15.10 \pm 3.40 / 5 \mathrm{~min}$ session. Also, the mean frequency of light and dark transitions for the caffeine-fed group of mice was $9.10 \pm 2.20 / 5 \mathrm{~min}$ session. This was significantly lower compared to the mean frequency of light and dark transitions in the LD transition box for the control group of mice $(\mathrm{p}<0.05$; Figure 7$)$.

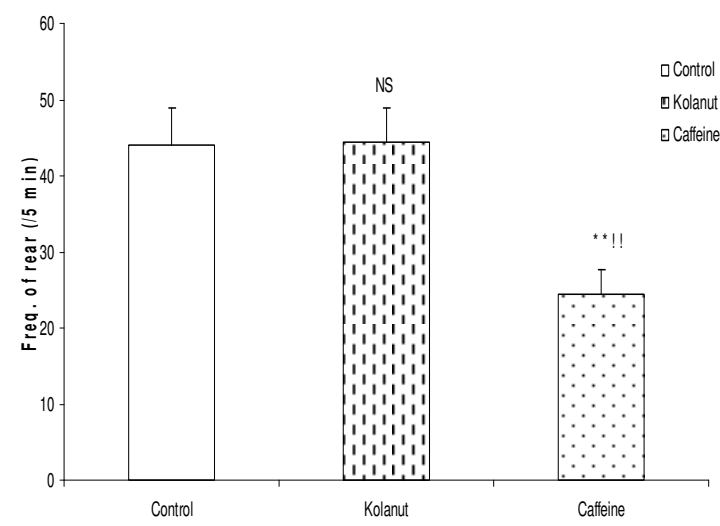

NS- Not significant compared to control; ** Significant at $p<0.01$ compared to control; !! Significant at $p<0.01$ compared to kola nut diet
FIG.5: Comparison of frequency of rearing in the open field apparatus for mice fed kola nut and caffeine diets and control.

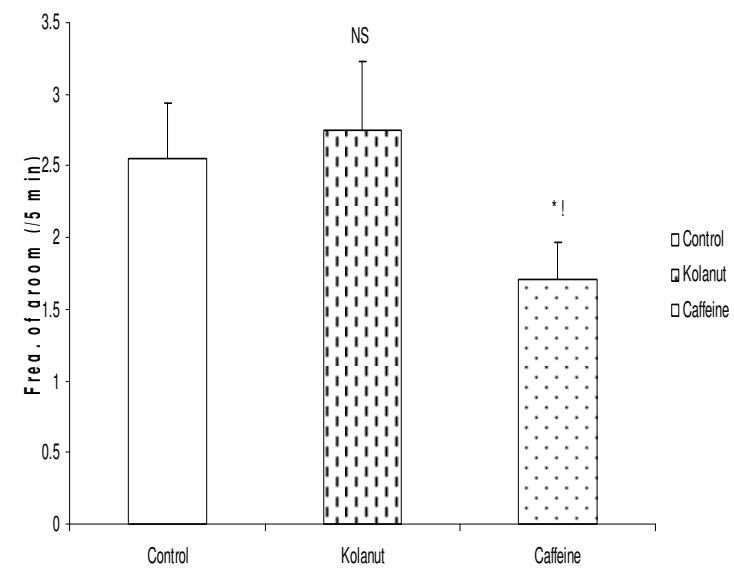

NS- Not significant compared to the control; * - Significant at $p<0.05$ compared to the control; ! - Significant at $p<$ 0.05 compared to the kola nut diet

Fig. 6: Comparison of frequency of grooming in the open field apparatus for the kola nut and caffeine diets fed mice and the control.

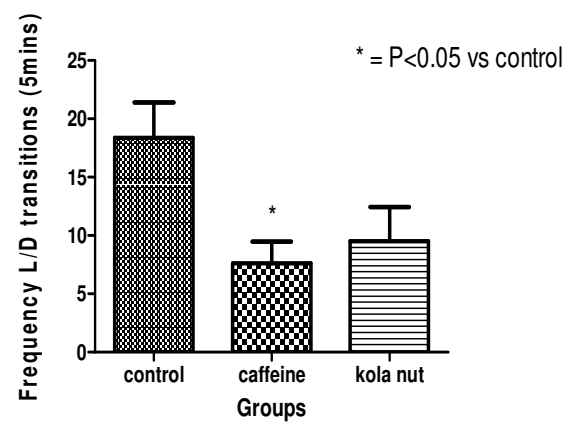

Fig. 7: Comparison of frequency of light-dark transitions in the light/dark transition box for kolanut and caffeine-fed mice

\section{Discussion:}

In order to assess the comparative effects of chronic (28 days) consumption of kola nut (Cola nitida) and caffeine diets on locomotor behaviour in mice, the open field apparatus and the light and dark transition box (LD) were employed. This method is 
Kola nut, caffeine, locomotor behaviour

in line with Brown et al. (1999), Archer (1973), Rodgers (1997) and Streng (1974), who used the open field apparatus to assess the locomotory and exploratory behaviour of animals in a novel environment. The locomotor behaviours scored in this study included line crossing, rearing, grooming and frequency of light-Dark transitions in the L/D transition box. The frequency of line crossing for the kola nut diet and caffeine diet-fed groups of mice did not differ significantly when compared to the control. However, the frequency of rearing and grooming for the caffeine-fed group was statistically lower compared to the control. The decrease in locomotor activity following chronic consumption of caffeine is in consonance with the reports of Neil (1978) which showed that chronic consumption of caffeine caused mixed depressive states in psychiatric patients. In support, the work of Greden et al (1978) also reported depressive syndrome following chronic consumption of caffeine. The depressive state is likely to lead to a decrease in locomotor and exploratory behaviour as shown by the results of this study. Reduced locomotor behaviour was shown by reduced rearing and grooming frequencies following chronic caffeine-diet consumption. Although caffeine is a stimulant, chronic consumption of caffeine leads to the development of tolerance Griffiths et al. (1988). Since the amount of caffeine consumed was not increased to maintain its stimulant action, it is conceivable that the mice were depressed after chronic consumption of same amount of caffeine as shown by the decrease in locomotion. The results of this study are also in consonance with the report of Sudakov et al. (2003) who reported a decrease in locomotor activity in the open-field test for fisher344 rats following chronic caffeine consumption. On the other hand, chronic consumption of kola nut-diet did not have any significant effect on locomotion. There are however, no previous studies in this regard.

The results also showed that chronic caffeinediet consumption decreased food intake, water intake and body weight when compared to the control group of mice. Chronic consumption of kola nut-diet also decreased food intake and body weight but not water intake when compared to the control group of mice. Kola nut and its active constituent, caffeine may possess appetite-suppressant effects and this effect produces weight loss in habitual users (Jessen et al. 2003; 2005). So, the decrease in body weight following chronic consumption of caffeine and kola nut diets may be due to the suppression of appetite in the animals. These results however, do not support the reports of Lopez-Garcia et al. (2006) who found an association between weights regain and habitual coffee consumption.
In conclusion, while consumption of kola nut diet by mice had no significant effect in locomotor behaviour, its active constituent, caffeine decreased locomotor behaviour. Furthermore, while kola nutdiet consumption decreased food intake and body weight but not water intake, caffeine decreased food intake, body weight change and water intake in mice. Therefore, the results obtained with kola nuts may not be due to caffeine alone. If these results are applicable to man, kola nut and caffeine consumption could be used to combat hunger and reduce body weight in obese persons.

\section{References:}

Archer, J. (1973). Test for Emotionality in Rats and Mice: A Review: Animal Behaviour, 21, 205235.

Brown, R.E. Corey, S.C. \& Moore A.K. (1999). Differences in Measures of Exploration and fear in MHC-Cogenic C57BL/6J and B6H-2K mice. Behaviour. Genetics, 29, 263-271.

Carrillo, J.A. and Bennitez, J. (2000). Clinically significant pharmacokinetic interactions between dietary caffeine and medications. Clin. Pharmacokinet., 39 (12), 127-153.

Eka, O.U. (1971). Prelilminary studies on the chemical composition of kola nut and bitter kola. A Ph.D. Project, Faculty of medicine, ABU, Zaria (pp10-25).

Gong, H., Simmons, M.S., Tashkin, D.P., Hui, K.K. and Lee, E.Y. (1986). Bronchodialator effects of caffeine in coffee. Chest, 89, 335-342.

Greden, J.F., Fountaine, P., Lubestky, M. and Chamberlin, K. (1978). Anxiety and depression associated with caffeinism among psychiatric inpatients. Am J. Psychiatry, 135, 963-966.

Griffiths, R.R. and Woodson, P.P. (1988). Caffeine physical dependence: a review of human and laboratory animal studies. Psychopharmacol. 94, 437-451.

Jessen, A.B., Toubro S. and Astrup A. (2003). Effect of chewing gum containing nicotine and caffeine on energy expenditure and substrate utilization in men. Am. J. Clin. 77, 1442-1447.

Jessen, A, Buemann B., Toubro S., Skovgaard, I.M. and Astrup, A. (2005). The appetite-suppressant effect of nicotine is enhanced by caffeine. Diabetes Obes. Metab. 7, 327-333.

Lopez-Garcia, E. Van Dam, R.M., Rajpathak, S., Willett, W.C., Manson, J.E. and Hu, F.B. (2006). Changes in caffeine intake and longterm weight change in men and women. Am. J. Clin. Nutr 83, 674-680.

Murat, I., Moriette, G. and Blin, M.c. (1986). Absorption rate of methylxanthines following 
capsules, cola and chocolate. Eur. J. Clin. Pharmacol., 51, 319-325.

Neil, J.F. (1978): Caffeinism complicating hypersonic depressive episodes. Comp. Psychiatry. 19, 337.

Osim, E.E. (2008). Neurophysiology (including 360 multiple choice questions and answers) $3^{\text {rd }}$ edition. University of Calabar press: Calabar ( $\mathrm{pp}$ 121).

Osim, E.E. and Udia, P.M. (1993): The effect of consuming kola nut (Cola nitida) diet on mean arterial pressure in rats. Int. J. Pharmacog. 31(3), 193-197.

Rodgers, R.J. (1997). Animal models of "anxiety": where next? Pharmacol. Biochem. Behav.: 8: 477-496.

Somorin, O. (1973). Caffeine content of Nigeria kola nuts. J. Food Sci. 38, 907-912.

Streng, J. (1974). Exploration and learning behaviours in mice selectively breed from high and low levels of activity. Behav. Genetics 4, 191-204.

Sudakov, S.J., Rusakova, I.V. and Medvedeva, O.F. (2003). Effect of chronic caffeine consumption on changes in locomotor activity of WAG/G and fischer-344 rats induced by nicotine, ethanol, and morphine. Bull.Exper. Biol. Med. 136, 563-565.

The Psychoactive Encyclopedia (2008): The history, usage, botanical and chemical aspects of psychoactive substance, fungi and plants. (Website: http//www.azarius.ed.net. on $17^{\text {th }}$ June, 2008).

Trindall, R. (1997). Ethno botanical leaflets: The culture of Cola: social and economic aspects of a West African domesticate Carbondale: Southern Illinois Universitiy Herbarium.

Walsh, R.N. and Cummins, R.A. (1976). The openfield test: a critical review. Psychol. Bull. 83: 482-504.

Westerterp-Plantenga, M.S., Lejeune, M.P. and Kovacs, E.M. (2005). Body weight loss and weight maintenance in relation to habitual caffeine intake and green tea supplementation. Obes. Res. 13: 1195-1204. 